\title{
INFLUENCE OF LPBF PROCESS PARAMETERS ON MILLING OF A MARAGING TOOL STEEL
}

\author{
M. Neuenfeldt ${ }^{1 *}$, F. Zanger ${ }^{1}$, V. Schulze ${ }^{1}$ \\ ${ }^{1}$ Karlsruhe Institute of Technology (KIT), wbk Institute of Production Science, Karlsruhe, Germany \\ ${ }^{\star}$ Corresponding author; manuela.neuenfeldt@kit.edu
}

\begin{abstract}
As the process parameters in the LPBF-process influence the microstructure, density and hardness of the produced parts, their influence on the milling process is suspected. For this reason the new maraging tool steel alloy Specialis ${ }^{\circledR}$ has been investigated on its machinability depending on the built parameters. The influence of the energy density, laser power and scan speed in the LPBF-process on the milling process Specialis ${ }^{\circledR}$ is examined. During the milling process the process forces are measured as well as the obtained surface roughness. The results confirm the importance of adjusting the process parameters in the LPBF-process to the finishing process.
\end{abstract}

\section{Keywords:}

Additive manufacturing; milling; Laser Powder Bed Fusion; maraging steel

\section{INTRODUCTION}

In tool manufacturing the additive manufacturing processes are getting more and more important as additive manufacturing allows the design and production of inner cooling channels and more complex and individual geometries. Due to the tolerances that can be achieved by metal additive manufacturing a finishing process is often needed to gain the necessary workpiece quality.

[Götze et al. 2018] and [Neuenfeldt et al. 2020] compared the cutting process of conventional and additively manufactured $316 \mathrm{~L}$, IN718 and Ti-6Al-4V. This parts were manufactured by Laser Powder Bed Fusion (LPBF) and machined in parallel and perpendicular to the build-up direction. Their studies showed a difference in the measured cutting forces, temperatures and obtained surface roughness between the conventionally produced parts and the additively manufactured parts for an orthogonal cutting process. The influence of the anisotropy of additive manufactured Ti-6Al-4V parts has also been investigated by [Lizzul et al. 2021]. The influence of the orientation of the part during slot milling has been investigated through the examination of the obtained surface. The different orientations lead to a comparable surface roughness $\mathrm{Sa}$ and a difference in the skewness Ssk.

In additive manufacturing the milling process is a commonly used finishing process. As shown previously for the orthogonal cutting process, milling of conventionally and additively manufactured parts leads to different surface roughness and process forces. [Milton et al. 2016] compared face milling of conventionally and additively manufactured Ti-6Al-4V parts. The additively manufactured parts showed higher process forces.

[Fortunato et al. 2018] investigated the influence of heat treatment on the process forces and surface roughness of LPBF maraging steel parts. The surface roughness of solution annealed parts and solution annealed and aged parts was $\mathrm{Sa}=8 \mu \mathrm{m}$ lower after the milling process than the surface roughness of the as-built parts. The solution annealed and aged parts showed higher process forces than the as-built parts and the solution annealed parts, because the aging process leads to a higher hardness of the parts. According to [Heisel et al. 2014] and [Montevecchi et al. 2016] the microstructure and the surface roughness of a part has a high impact on the machinability. As the microstructure and the surface roughness of additively manufactured parts depends on the process parameters during manufacturing, these influences should be taken into account while investigating the machinability of new materials in LPBF.

The influence of the process parameters in the LPBFprocess is object of many research works. By increasing the energy density during the LPBF process of a maraging steel, the hardness of the part increases and the surface roughness decreases [Casalino et al. 2015]. Here the energy density is based on the laser power, the scan speed and the hatch distance. [Graf et al. 2021] showed the influence of those parameters on the microstructure and the density of Specialis $₫$ SLM-Alloy 2 parts and [Agapovichev et al. 2018] showed the influence of the laser power, scan speed and hatch distance on the hardness and tensile strength of $150 \mathrm{Cr} 14$ LPBF-parts. These works show that 
Tab. 1: Chemical composition of the maraging tool steel Specialis ${ }^{\circledR} S L M-A l l o y 2$

\begin{tabular}{lllllllll}
\hline Elements & $\mathbf{F e}$ & $\mathbf{C}$ & $\mathbf{N i}$ & Co & Mo & V & Ti & Al \\
\hline wt $\%$ & Balance & $<0.1$ & $<25$ & $<20$ & $<8$ & $<5$ & $<3$ & $<1$ \\
\hline
\end{tabular}

the process parameters of the LPBF process have a significant influence on the microstructure.

[Lizzul et al. 2020] showed the influence of the scan strategy on the surface integrity of machined Ti-6Al-4V LPBF-parts by comparing a stripe and island based scan strategy. In this work the LPBF microstructure has been influenced by the scan strategy which mostly influenced the machined surface roughness.

In this paper the influence of the LPBF parts on the finishing process of a maraging tool steel is investigated. The influence of the energy density, the laser power and the scan speed on the milling process of Specialis $®$ SLMAlloy 2 is shown by measuring the process forces and the surface roughness.

\section{MATERIALS AND METHODS OF RESEARCH}

\subsection{Specimen preparation}

The investigated material is a maraging tool steel specially designed for an enhanced processability in LPBF machines by SpecMaterials. The chemical composition of Specialis ${ }^{\circledR}$ SLM-Alloy 2 is shown in 'Tab. 1'.

To determine the LPBF process parameters for each test specimen a variation based on the volume energy density $\mathrm{E}_{\mathrm{v}}$ by [Meiners 1999] is undertaken:

$E_{V}=\frac{P_{L}}{v_{S} * h_{S} * l_{S}}$

The volume energy density depends on the laser power $P_{L}$, the scan speed vs, the hatch distance hs and the layer thickness Is. According to [Graf et al. 2021] the laser power and the scan speed have the biggest impact on the microstructure and the density of Specialis ${ }^{\circledR}$ SLM-Alloy 2 parts. The milling test specimens have been manufactured with various values of laser power and scan speed 'Tab. 2', leading to different volume energy densities. The variation was made around the standard process parameters ' $T a b$. 2, A' developed by [Graf et al. 2021] and is based on a CCD experimental plan.

The test specimen were produced by selective laser melting on a SLM $280 \mathrm{HL}$ Twin ( $400 \mathrm{~W}$ ) by SLM Solutions Group AG with $200^{\circ} \mathrm{C}$ build plate preheating using the stripes scanning strategy and a constant layer thickness of $\mathrm{I}_{\mathrm{S}}=30 \mu \mathrm{m}$ as well as a constant hatch distance of $\mathrm{h}_{\mathrm{s}}=0,12 \mathrm{~mm}$.

The test specimen geometry is shown in 'Fig. 1'. To compare different thicknesses of parts the test specimen is divided in three parts 'Fig. 1 a)'. On each part of the test specimen circumferential milling can be investigated with one path as shown 'Fig. 1 b)'. For each process parameter set five test specimen were manufactured.

The test specimen were manufactured twice. Half of the test specimen were aged at $495^{\circ} \mathrm{C}$ for $8 \mathrm{~h}$ in a protective argon atmosphere.
Tab. 2: LPBF process parameters

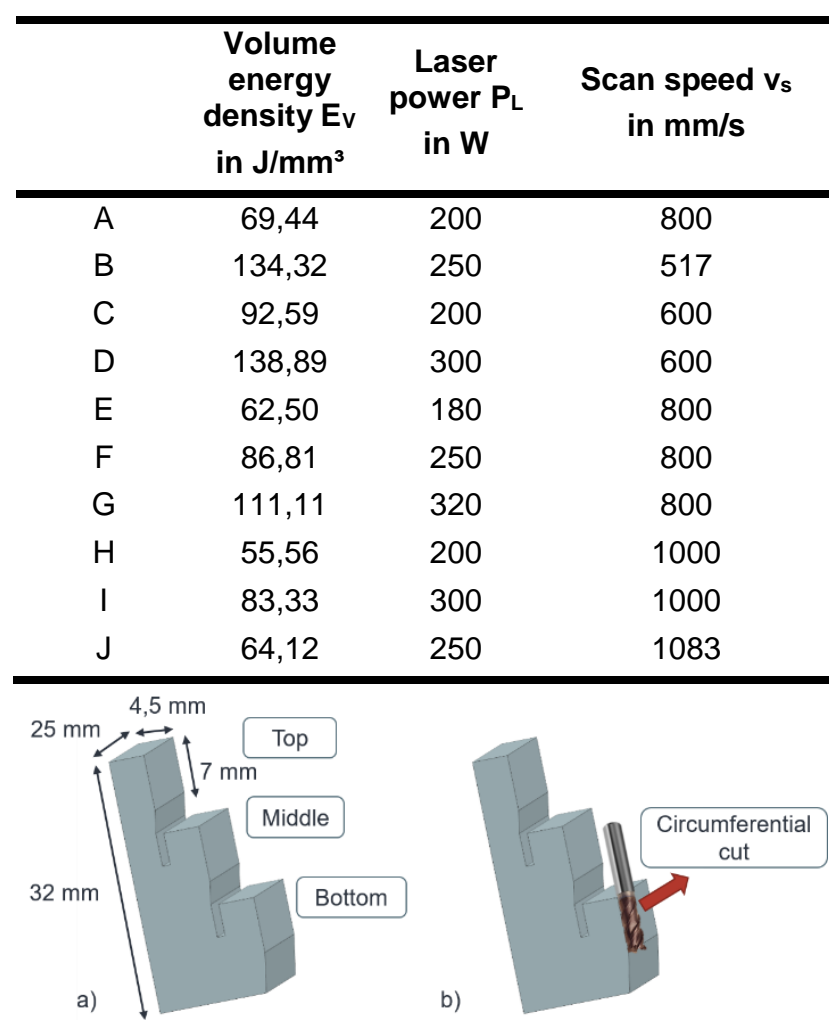

Fig. 1: Test specimen geometry

\subsection{Milling test set up}

For the milling tests, two cutting speeds and two feed rates as well as a constant radial depth of cut $\mathrm{a}_{\mathrm{e}}=0,05 \mathrm{~mm}$ and a constant axial depth of cut $a_{p}=0,1 \mathrm{~mm}$ were selected based on the recommendation of the tool manufacturer for a finishing process. The parameter sets for the milling tests are shown in 'Tab. 3'.

Tab. 3: Milling parameters

\begin{tabular}{cc}
\hline Cutting speed in $\mathbf{~} / \mathbf{m i n}$ & Feed in $\mathbf{~ m}$ /teeth \\
\hline 80 & 0,022 \\
80 & 0,032 \\
120 & 0,022 \\
120 & 0,032 \\
\hline
\end{tabular}

The milling tests were carried out on a 3-axis Heller MC16 machine with RF100H end mills from Gühring with a diameter of $10 \mathrm{~mm}$. The specimens were mounted directly on a force measurement platform, as shown in 'Fig. 2'. During the milling process, the process forces were recorded in the three spatial directions using a Kistler force measurement platform. To evaluate the measured data for 
the process forces, an area of use is defined. The area of use describes $80 \%$ of the collected data in order to cut off the signals measured during the entry and the exit of the end mill. These area of use is then calculated to one revolution of the end mill so that a mean value of the force can be calculated for the period where the end mill is in contact with the part.

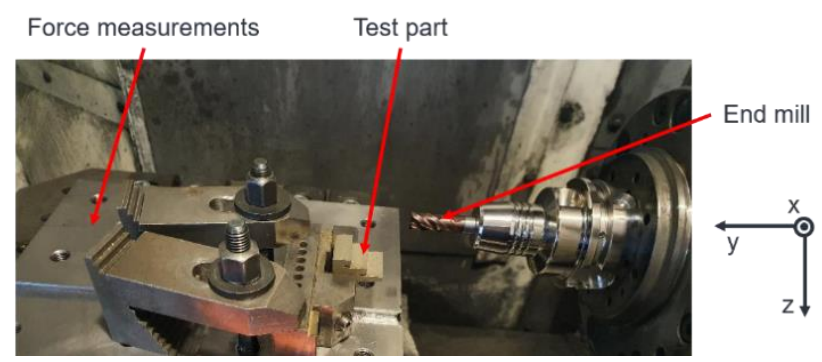

Fig. 2: Experimental set up with force measurements

Three circumferential cuts were made for each specimen and stair tread in order to compare the three milling positions. Here, the lower stair tread is directly at the clamping, while the upper stair tread protrudes furthest from the clamping 'Fig. 2'. Every cuts were performed with new end mills to avoid an influence of the tool wear on the results of the experiments shown.

The measurements of the surface roughness were made after the milling process using a confocal microscope system $\mu$ surf Custom (NanoFocus AG).
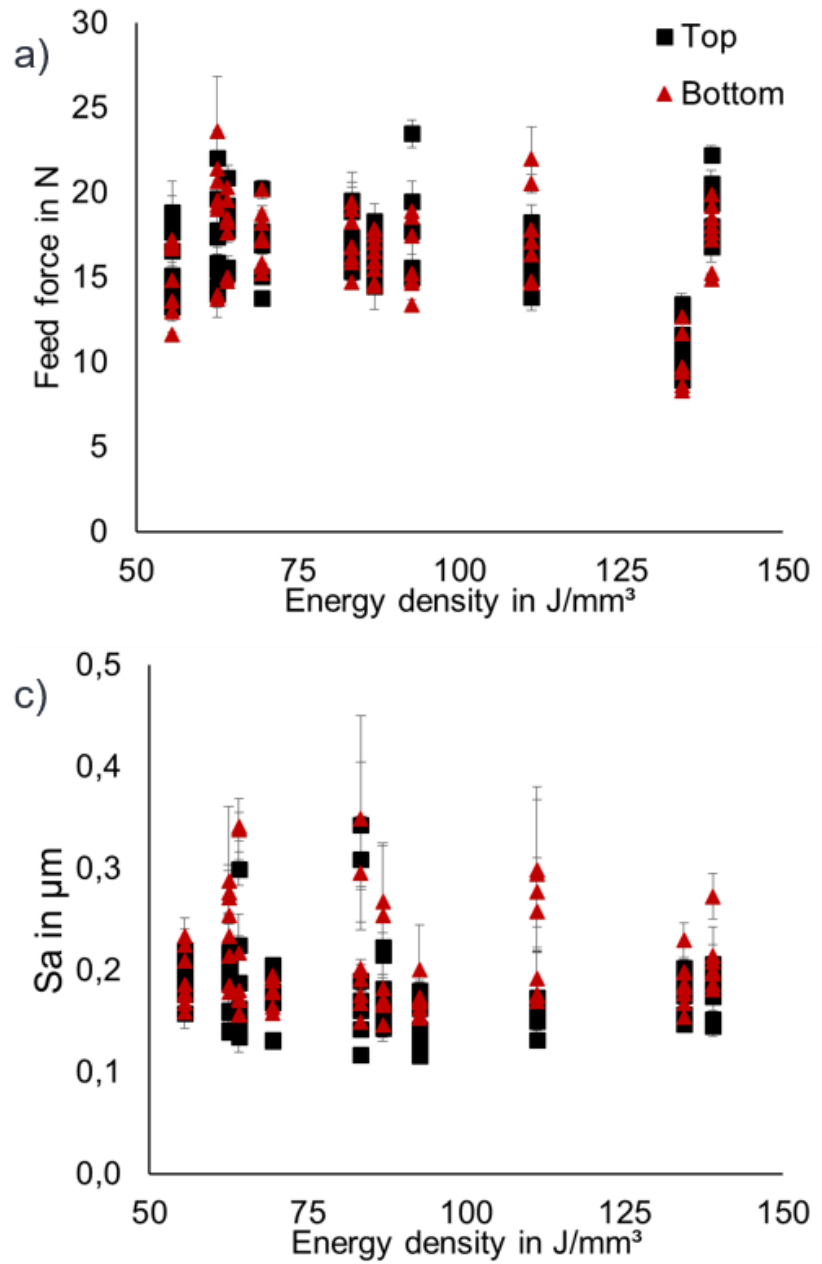

The porosity of each specimen and stair tread has been measured by analyzing micrographs on three different sections.

To analyze the microstructure of the test specimen were etched with natal.

\section{RESULTS AND DISCUSSION}

First the results of the circumferential cut are discussed and the influence of the LPBF process parameters such as the energy density, the laser power and the scan speed are shown on the feed force, the cutting force and the surface roughness Sa. Each investigated point was measured three times. In the following figures the calculated mean value and the standard deviation is shown.

\subsection{Comparison of the top and bottom part of the test specimen}

The top and the bottom stair tread is compared as they represent the extrema of the investigated geometry.

'Fig. 3' shows that the thickness of the part and the protruding of the machined surface has no significant influence on the feed force. Both process forces are mostly in the same range for the top and the bottom stair tread of the part. The roughness at the top shows slightly lower values for all values of the energy density. Moreover, the roughness standard deviation is increased at the highest value of the laser power $\mathrm{PL}$ for a constant scan speed Vs. This can be seen for every process parameter set. The surface at the bottom part of the test specimen shows a
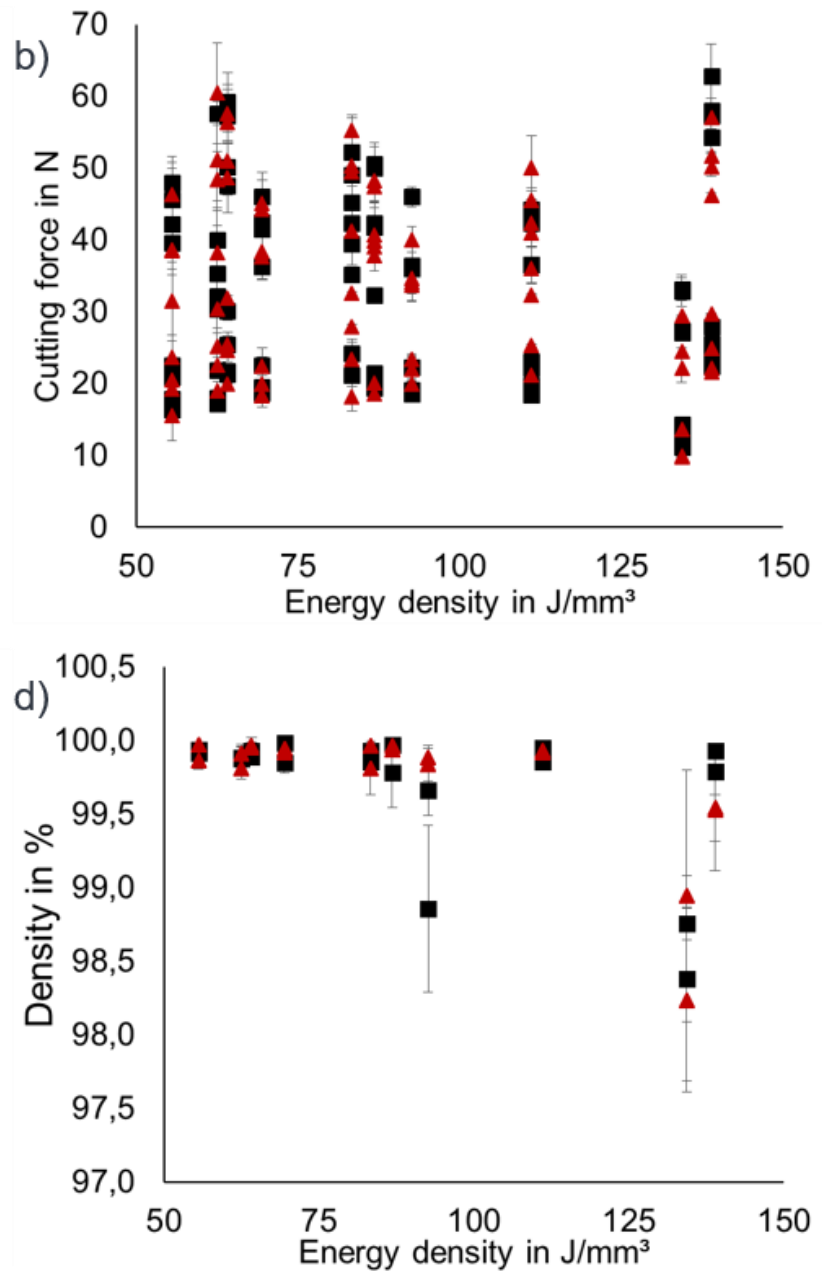

Fig. 3: Process forces a) and b), surface roughness c) and density d) for cutting speeds from 80 to $120 \mathrm{~m} / \mathrm{min}$ and feed rates from 0,022 to 0,032 $\mathrm{mm} /$ teeth depending on the energy density of the top and bottom stairs of the test specimen. 
higher standard deviation as the top part. This is due to a higher porosity in this part of the test specimen. 'Fig. 3 ' shows that the lower process forces for the test specimen produced with an energy density $\mathrm{E}_{\mathrm{v}}=134,32 \mathrm{~J} / \mathrm{mm}^{3}$ and $\mathrm{E}_{\mathrm{V}}=138,89 \mathrm{~J} / \mathrm{mm}^{3}$ is due to a higher porosity in the parts.

The pores appearing for the parts with an energy density $E_{v}=134,32 \mathrm{~J} / \mathrm{mm}^{3}$ (Parameter $\mathrm{B}$ ) are gas pores due to the high energy density 'Fig. 4'. The micrographs of the aged specimen in 'Fig. 4' show a regular microstructure for every level of energy density (low $\mathrm{Ev}=55,56 \mathrm{~J} / \mathrm{mm}^{3}$, medium $E_{v}=92,59 \mathrm{~J} / \mathrm{mm}^{3}$ or high $E_{v}=134,32 \mathrm{~J} / \mathrm{mm}^{3}$ ). For an energy density $E_{v}=134,32 \mathrm{~J} / \mathrm{mm}^{3}$ (Parameter B) a difference between the top part and the bottom part of the test specimen can be seen. The top stair tread shows more gas pores and a higher porosity than the bottom stair tread. This is due to the thinner surface scanned during the LPBFprocess which leads to a lower cooling time between the layers in the process and results in a higher energy induced in the part.

In the following the results of the top stair tread of the test specimen are shown and discussed in detail.

\subsection{Influence of the energy density}

At first the microstructure, the feed and cutting force and the surface roughness of the top stair tread of the test specimen are compared depending on the energy density used during the LPBF-process. The energy density expresses the amount of energy induced in the part during the LPBFprocess.

\section{Microstructure}

'Fig. 4' shows the microstructure of the aged test specimen for a low $E_{v}=55,56 \mathrm{~J} / \mathrm{mm}^{3}$, medium $E_{v}=92,59 \mathrm{~J} / \mathrm{mm}^{3}$ or high $E_{v}=134,32 \mathrm{~J} / \mathrm{mm}^{3}$ energy density. Comparing the test specimen with the low energy density $E_{v}=55,56 \mathrm{~J} / \mathrm{mm}^{3}$ (Parameter $\mathrm{H}$ ) to the high energy density $E_{v}=134,32 \mathrm{~J} / \mathrm{mm}^{3}$ (Parameter B) a difference in the pore geometry can be observed. Parameter $\mathrm{H}$ shows lack of fusion pores. These pores have a long and thin geometry. It is assumed that a low energy density leads to lack of fusion pores as the energy given into the powder bed is too low to remelt the underlying layer. A high energy density leads to fusion pores or gas pores as the energy in the melt pool is too high and the emerging gas stays in the melt pool (Parameter B).

The parameter $\mathrm{C}$ which represents a middle level of energy density shows some gas and some lack of fusion pores but has aver all a high density as shown in 'Fig. 3'.

\section{Process forces}

'Fig. 5 a) and b)' shows a correlation between the energy density and the process forces. The highest process forces are measured during machining of parts processed with a volume energy density of 75 and $100 \mathrm{~J} / \mathrm{mm}^{3}$. A higher porosity after the LPBF-process leads to lower process forces during machining of those parts.

'Fig. 5' shows that the feed force of the as-built and aged test specimen are in a similar range, whereas the cutting forces for the aged test specimen are higher than for the asbuilt parts. This increase in the cutting force is probably due to an increase of hardness in the test specimen. [Graf et al. 2021] showed that the Specialis $®$ SLM-Alloy 2 parts increase about 12 to $27 \mathrm{HRC}$ in hardness with the heat treatment.

\section{Surface roughness}

The surface roughness of the as-built and aged parts is in a similar range. For the as-built parts the lowest surface roughness can be achieved with an energy density between 75 and $100 \mathrm{~J} / \mathrm{mm}^{3}$ 'Fig. 5'. As for the cutting forces it is assumed that a low energy density leads to lack of fusion pores and a high energy density leads to gas pores. A higher porosity after the LPBF-process leads to a higher surface roughness after machining those parts. At a volume energy density $E_{v}=92,59 \mathrm{~J} / \mathrm{mm}^{3}$, the lowest roughness is present for the parameter $\mathrm{C}$.

As discussed before, except for the parts with the highest volume energy density the cutting forces of all the parts follow a curve with the maximum for an energy density between 75 and $100 \mathrm{~J} / \mathrm{mm}^{3}$ 'Fig. 5 a)'. This correlates with the obtained surface roughness after milling. It is assumed
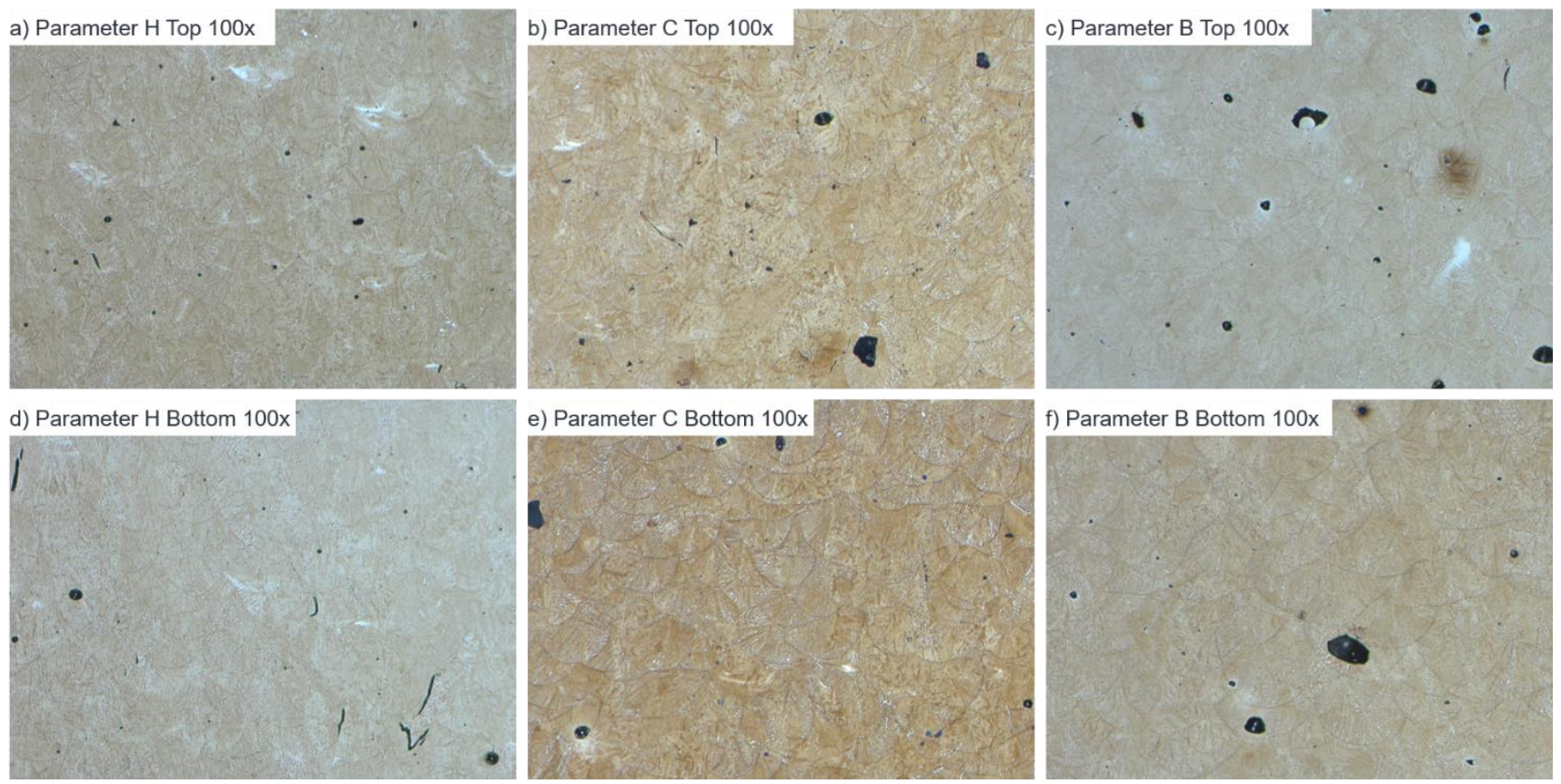

Fig. 4: Microstructure of the aged test specimen with a magnification of 100 of the top stair tread a) to c) and bottom stair tread d) to f) of a low energy density $E V=55,56 \mathrm{~J} / \mathrm{mm}^{3}$ a) and d); a middle energy density $E V=92,59 \mathrm{~J} / \mathrm{mm}^{3} \mathrm{~b}$ ) and e); a high energy density $E V=134,32 \mathrm{~J} / \mathrm{mm}^{3} \mathrm{c}$ ) and f) 

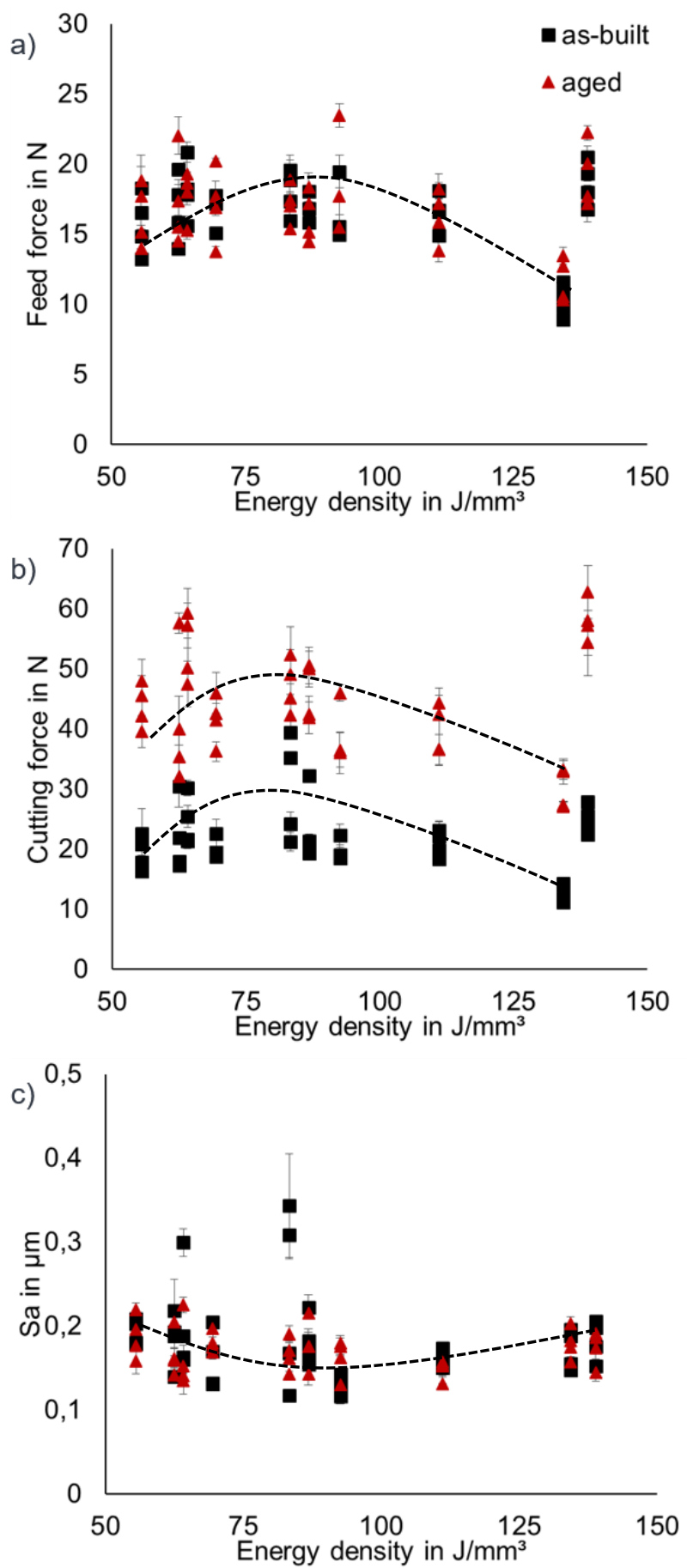

Fig. 5: Process forces a) and b) and surface roughness c) of the top stair tread of the test specimen for cutting speeds from 80 to $120 \mathrm{~m} / \mathrm{min}$ and feed rates from 0,022 to $0,032 \mathrm{~mm} /$ teeth depending on the energy density for asbuilt and aged parts.

that parts with a lower porosity induce higher process forces and lead to a lower surface roughness.

For a better understanding of the different process forces and surface roughness obtained a closer look to the isolated LPBF parameters laser power and scan speed is needed.

\subsection{Influence of the laser power}

In the following the results from the top stair tread of the as built and aged test specimen are shown depending on the laser power. The results for a constant scan speed vs $=800 \mathrm{~mm} / \mathrm{s}$ 'Fig. 6' are further discussed.

\section{Cutting force}

The cutting force during milling of the as-built parts shows different correlations with the laser power depending on the cutting force and the feed rate 'Fig. 6 a)'.

A high feed rate leads to higher cutting forces over all the investigated cutting speeds 'Fig. 6 a)' and 'Fig. 6 b)'.

For the as-built parts cutting forces during milling with a cutting speed $v_{c}=120 \mathrm{~m} / \mathrm{min}$ are higher than at a cutting speed $v_{c}=80 \mathrm{~m} / \mathrm{min}$. As expected milling with the highest cutting speed and feed rate shows the highest cutting force 'Fig. 6 a)'. For the as-built parts a bigger influence of the milling parameters than of the LPBF parameters on the cutting force can be assumed.

Considering the aged parts the cutting force is the highest for a middle laser power $\left(P_{L}=250 \mathrm{~W}\right)$ and the lowest for high and low laser power 'Fig. 6 b)'. The same correlations can be done with the density of maraging tool steels. It is assumed that the parts produced with a low and high laser power have a higher porosity that leads to lower cutting forces. Except the cutting forces measured at a cutting speed of $v_{c}=120 \mathrm{~m} / \mathrm{min}$ and a feed rate of $f_{z}=0,032 \mu \mathrm{m}$ all the milling parameter sets show the same correlation between the cutting force and the laser power. For those parameter sets the highest cutting force at $P_{L}=250 \mathrm{~W}$ is $10 \mathrm{~N}$ higher than the lowest. 'Fig. 6 b)' also shows that $0,01 \mathrm{~mm}$ higher feed rates lead to $10 \mathrm{~N}$ higher cutting forces.

With increasing feed rate, the forces also increase, whereby the cutting speed has no great influence.

Especially at low laser power, a force peak appears with very strong cutting parameters 'Fig. 6 b)'. It is supposed that the force peak is due to non-melted powder. The median particle size of the powder is $d_{50}=33,0 \mu \mathrm{m}$ for a particle size distribution from $14,6 \mu \mathrm{m}$ to $51,9 \mu \mathrm{m}$ [Graf et al. 2021]. The feed rate corresponds to the particle diameter and very hard particles could break out of the base material. The tendency to increasing forces can also be seen at a cutting speed $\mathrm{v}_{\mathrm{c}}=80 \mathrm{~m} / \mathrm{min}$ the same feed rate $\mathrm{f}_{\mathrm{z}}=0,032 \mu \mathrm{m}$.

\section{Surface roughness}

In 'Fig. $6 \mathrm{c}$ )' the standard variation of the surface roughness of the part produced with a laser power $\mathrm{PL}_{\mathrm{L}}=180 \mathrm{~W}$ and finished with a cutting speed $v_{c}=80 \mathrm{~m} / \mathrm{min}$ and a feed rate $f_{z}=0,022 \mu \mathrm{m}$ is very high compared to the others. This could be because of the higher porosity in the part due to low laser power. It is assumed that the low cutting speed and feed rate cannot change the topography of the surface significantly. For cutting speeds $\mathrm{v}_{\mathrm{c}}=80 \mathrm{~m} / \mathrm{min}$ a laser power around $200 \mathrm{~W}$ leads to the lowest surface roughness. Laser power should not be less than $200 \mathrm{~W}$, otherwise the surface roughness will increase, probably due to more pores in the part.

Except for the parameter set with a cutting speed $V_{c}=80 \mathrm{~m} / \mathrm{min}$ and a feed rate $\mathrm{f}_{\mathrm{z}}=0,022 \mu \mathrm{m}$, the surface roughness is the highest for the parts produced with a middle laser power $P_{L}=250 \mathrm{~W}$. At a cutting speed $v_{c}=80 \mathrm{~m} / \mathrm{min}$ and a feed rate $\mathrm{f}_{\mathrm{z}}=0,022 \mu \mathrm{m}$ the surface roughness is at the lowest for a middle laser power $P L=250$ W 'Fig. 6 d)'. 

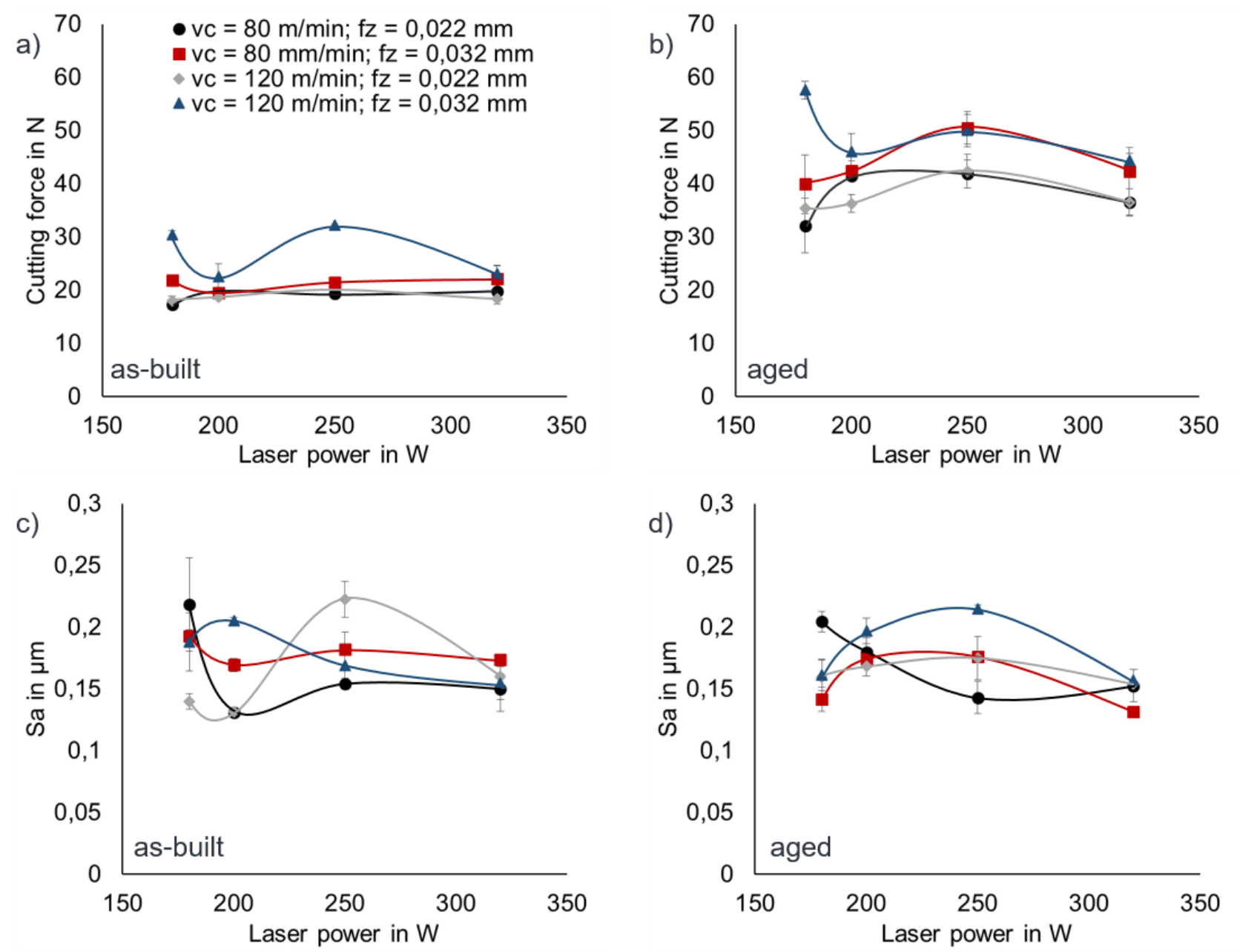

Fig. 6: Cutting force (a) and b)) and surface roughness (c) and d)) of the top stair tread of the as-built (a) and c)) and aged (b) and d)) test specimen depending on the laser power at a scan speed $v S=800 \mathrm{~mm} / \mathrm{s}$.

\subsection{Influence of the scan speed}

In the following the results from the top stair tread of the asbuilt and aged test specimen are shown depending on the scan speed. The results for a constant laser power $\mathrm{PL}=200 \mathrm{~W}$ 'Fig. 7' are further discussed.

\section{Cutting force}

At $\mathrm{v}_{\mathrm{s}}=1000 \mathrm{~mm} / \mathrm{s}$ the standard deviations for all cutting speeds and feed rates are the highest 'Fig. 7 a)' and 'Fig. 7 b)'. A high scan speed leads to higher porosity in the part [Graf et al. 2021]. Due to the higher speed of the laser spot less energy can be induced into the powder bed and lack of fusion pores can occur. Lack of fusion pores are usually bigger than gas pores and could have an influence on the cutting forces, so that the cutting force is significantly lower when a lack of fusion pore is on the machine surface.

The influence of the scan speed on the cutting force is not as pronounced as for the laser power. Nevertheless, higher scan speeds lead to higher cutting forces but the correlation is not the same for every milling parameter set. The parameter sets with a feed rate $f_{z}=0,022 \mu \mathrm{m}$ show opposite correlations for the aged parts. For a low cutting speed, the highest cutting force is at a middle scan speed vs $=800 \mathrm{~mm} / \mathrm{s}$ 'Fig. $7 \mathrm{~b}$ )'.

Comparing as-built and aged parts, the effects remain similar. However, the different milling strategies are significantly further apart at very high and very low scan speeds. A low scan speed should be selected in order to keep the forces low.

\section{Surface roughness}

The surface roughness of the as-built parts is increasing by $\mathrm{Sa}=0,1 \mu \mathrm{m}$ with the scan speed 'Fig. $7 \mathrm{c}$ )'. The surface roughness of the parts is mostly higher for parts processed at a higher feed rate.

In 'Fig. 7 c)' higher scan speeds lead to a higher surface roughness for parts machined with a higher feed rate. Parts machined with a lower feed rate show a minimum at a scan speed of $v_{s}=800 \mathrm{~mm} / \mathrm{s}$. Considering a cutting speed $v_{c}=80 \mathrm{~m} / \mathrm{min}$ and a feed rate $f_{z}=0,032 \mathrm{~mm}$ the lowest surface roughness appears at a scan speed $v_{s}=600 \mathrm{~mm} / \mathrm{s}$. The scan speed must be reduced with increasing feed rate to achieve minimum surface roughness.

As for the as-built parts the surface roughness of the heat treated parts increases with an increasing scan speed 'Fig. $7 \mathrm{~d}$ )'. When exceeding a critical cutting speed to feed rate ratio at very low scan speeds, the process forces increase and this also tends to lead to a higher surface roughness than at low ratios. At a laser power $P_{L}=200 \mathrm{~W}$ and a scan speed $v_{s}=600 \mathrm{~mm} / \mathrm{s}$, the lowest roughness is present for the parameter $\mathrm{C}$.

Comparing 'Fig. 7 c)' and 'Fig. 7 d)' a correlation between the cutting force and the surface roughness can be assumed. For this reason the cutting force can be used to predict the surface roughness of the part. 

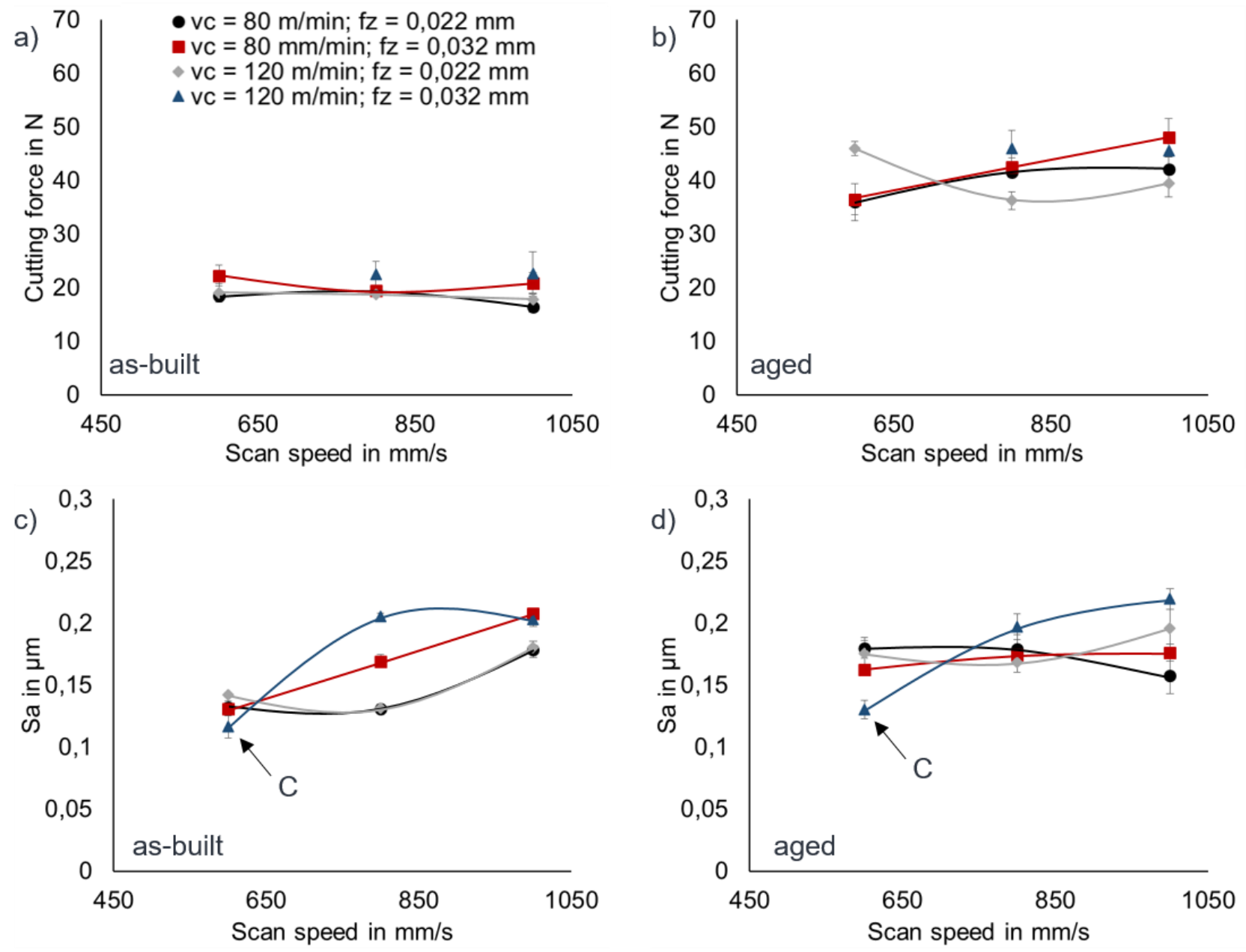

Fig. 7: Cutting force (a) and b)) and surface roughness (c) and d)) of the top stair tread of the as-built (a) and c)) and aged (b) and d)) test specimen depending on the scan speed at a laser power $P L=200 \mathrm{~W}$.

\section{CONCLUSION}

The results of this paper show the influence of the LPBF process parameters on the milling process of the new maraging tool steel Specialis ${ }^{\circledR}$ SLM-Alloy 2. Therefore, test specimen with different volume energy density due to a variation of the laser power and the scan speed are produced by laser powder bed fusion. The test specimen are machined with four different parameter sets based on two cutting speeds and two feed rates. Additionally, as-built and heat treated parts are compared as maraging tool steels commonly need a heat treatment after the LPBFprocess. The cutting forces and surface roughness are measured and analyzed. The main conclusions of this investigations are:

1. The cutting forces have a maximum at a middle laser power $P_{L}=250 \mathrm{~W}$ and a middle volume energy density $E_{v}$ between 75 and $100 \mathrm{~J} / \mathrm{mm}^{3}$.

2. The lowest surface roughness occurs at a middle volume energy density $E_{v}$ between 75 and $100 \mathrm{~J} / \mathrm{mm}^{3}$.

3. For the most milling parameter sets the surface roughness increases with increasing scan speeds for as-built and heat treated parts.

4. LPBF process parameters that lead to higher porosity induce lower cutting forces.

The results achieved are in line with similar studies in the literature concerning the influence of the cutting speed and feed force on the process forces and the surface roughness of the machined parts.

The results show that a low cutting speed and a low feed rate lead to a high surface quality while machining LPBF parts produced with standard LPBF parameters.

Further investigations on the microstructure and the hardness of the parts needs to be done to confirm the hypothesis made in this work.

\section{ACKNOWLEDGMENTS}

The research project "Design of high-performance tool steel metal powders for Laser Additive Manufacturing (HiPTSLAM)" is funded by the Federal Ministry of Education and Research (BMBF) in the program "Internationalisation of Leading-Edge Clusters, Forward-Looking Projects and Comparable Networks (InterSpiN)" of Leichtbau-BW under the funding code 03INT614A and supervised by Project Management Jülich (PTJ).

With the kind support of Rosswag engineering partner in the HiPTSLAM research project for producing the test specimen and developing the standard parameter set for the LPBF-process.

\section{REFERENCES}

[Agapovichev et al. 2018] Agapovichev, A. V., Sotov, A. V., Kyarimov, R. R., Alexeev, V. P., Smelov, V. G., Sufiiarov, V. S., Masaylo, D. V. The investigation of microstructure 
and mechanical properties of tool steel produced by selective laser melting Technology. Materials Science and Engineering, 2018, Vol. 441

[Casalino et al. 2015] Casalino, G., Campanelli, S. L., Contuzzi, N., Ludovico, A. D. Experimental investigation and statistical optimisation of the selective laser melting process of a maraging steel. Optics\& Laser Technology, 2015, Vol. 65, pp 151-158

[Fortunato et al. 2018] Fortunato, A., Lulaj, A., Melkote, S., Liverani, E., Ascari, A., Umbrello, D. Milling of maraging steel components produced by selective laser melting. Int $J$ adv Manuf Technol, 2018, Vol. 94, pp 1895-1902

[Goetze et al. 2018] Goetze, E., Zanger, F., and Schulze, V. Orthogonal cutting of laser beam melted Parts. AIP Conference Proceedings 1960, 070023 (2018); https://doi.org/10.1063/1.5034919; Published Online: 03 May 2018

[Graf et al. 2021] Graf, G., Neuenfeldt, M., Mueller, T., Fischer-Buehner, J., Beckers, D., Donisi, S., Zanger, F., Schulze, V. Efficient Qualification Strategy of New Steel Alloys for Laser Powder Bed Fusion. Advanced Materials Research, 2021, Vol. 1161, pp 27-36

[Heisel et al. 2014] Heisel, U., Klocke, F., Uhlmann, E., Spur, G. Handbuch Spanen. (C) Carl Hanser Verlag, München 2014. ISBN: 978-3-446-42826-3
[Lizzul et al. 2020] Lizzul, L., Bertolini, R., Ghitotti, A, Bruschi, S. Effect of AM-induced Anisotropy on the Surface Integrity of Laser Powder Bed Fused Ti6Al4V Machined Parts. In Procedia Manufacturing, 2020, Vol. 47. Pp. 505510

[Lizzul et al. 2021] Lizzul, L., Sorgato, M., Bertolini, R., Ghitotti, A, Bruschi, S. Anisotropy effect of additively manufactured Ti6AI4V titanium alloy on surface quality after milling. In Precision Engineering, January 2021, Vol. 67, pp. 301-310

[Milton et al. 2016] Milton, S., Morandeau, A., Chalon, F., Leroy, R. Influence of finish machining on the surface integrity of Ti6Al4V produced by Selective Laser Melting. Procedia CIRP 45, 2016, pp 127-130

[Montevecchi et al. 2016] Montevecchi, F., Grossi, N., Takagi, H., Scippa, A., Sasahara, H., Campatelli, G. Cutting forces analysis in additive manufactured AISI H13 alloy. Procedia CIRP, 2016, Vol. 46, pp. 476-479

[Neuenfeldt et al. 2020] Neuenfeldt, M., Zanger, F., Schulze, V. Machining of Hybrid (Conventionally and Additively) built 316L, IN718 and Ti-6Al-4V Specimen. HTM J. Heat Treatm. Mat., March 2020, Vol. 75, pp. 192-203. DOI:10.3139/105.110411 